\title{
Adjust pH Dosing Unit
}

National Cancer Institute

\section{Source}

National Cancer Institute. Adjust pH Dosing Unit. NCI Thesaurus. Code C48472.

A dosing unit based on an adjustment in the $\mathrm{pH}$. 